\title{
Expectation and satisfaction of HIV/AIDS patients toward the pharmaceutical care provided at Gondar University Referral Hospital, Northwestern Ethiopia: a cross-sectional study
}

\author{
This article was published in the following Dove Press journal: \\ Patient Preference and Adherence \\ 5 October 2016 \\ Number of times this article has been viewed
}

\author{
Tamrat Befekadu Abebe' \\ Daniel Asfaw Erku² \\ Begashaw Melaku \\ Gebresillassie' \\ Kaleab Taye Haile ${ }^{3}$ \\ Abebe Basazn Mekuria ${ }^{4}$ \\ 'Department of Clinical Pharmacy, \\ ${ }^{2}$ Department of Pharmaceutical \\ Chemistry, ${ }^{3}$ Department of \\ Pharmaceutics, ${ }^{4}$ Department \\ of Pharmacology, School of \\ Pharmacy, University of Gondar, \\ Gondar, Ethiopia
}

Purpose: Measurements of patient satisfaction help to assess the performance of health service provision and predict treatment adherence and outcomes. This study aimed to assess human HIV/AIDS patients' expectation of and satisfaction with the pharmaceutical service delivered at Gondar University Referral Hospital, Ethiopia.

Patients and methods: An institution-based cross-sectional study was performed from May 11 to 25, 2015. A total of 291 patients living with HIV/AIDS were included using a simple random sampling method. Data were collected using structured questionnaires measuring expectation and satisfaction of respondents using a Likert scale of 1-5 through face-to-face interviews. The data collected were entered into and analyzed using Statistical Packages for Social Sciences. Comparison was made between those respondents who lived in and outside the town.

Results: The overall mean expectation and satisfaction of respondents toward pharmacy setting and services were 3.62 and 3.13, respectively. More than half (56.1\%) of the participants were dissatisfied with the comfort and convenience of waiting area and private counseling room. Similarly, $69.3 \%$ of the respondents claimed that pharmacy professionals did not give information about side effects and drug-drug and drug-food interactions of antiretroviral medications. There was a statistically significant difference between respondents who live in and outside Gondar town in overall expectation $(t=3.415, P=0.001)$ with the pharmacy setting and services.

Conclusion: In this study, the overall satisfaction level of respondents with pharmaceutical service (pharmacy setting and services) provided at Gondar University Referral Hospital was found to be low, while the overall respondents' expectation from the pharmaceutical services were exceedingly high. The hospital should implement good dispensing practice systems in relation to the services and continuing professional development to professionals in order to improve the satisfaction of patients.

Keywords: pharmaceutical care, Ethiopia, HIV/AIDS, antiretroviral therapy

\section{Introduction}

HIV infection affects residents of all countries of the world, but the greater majority of affected individuals reside in the developing countries. ${ }^{1} \mathrm{HIV}$ has globally claimed $>20$ million lives, and currently $>34$ million people are living with the infection. Even though HIV/acquired immunodeficiency syndrome (AIDS) remains a worldwide pandemic, Ethiopia is one of the highly affected Sub-Saharan countries. ${ }^{2,3}$ In 2014, the national HIV/AIDS prevalence in Ethiopia was 1.14\%, and the estimated
Correspondence: Tamrat Befekadu Abebe

Department of Clinical Pharmacy, School of Pharmacy, University of Gondar, Lideta Kebele 16, PO Box 196, Gondar, Ethiopia Fax +25158 II4 I240

Email befekadutamrat@gmail.com 
number of people living with HIV was 769,600, with 15,700 new HIV infections and 35,600 AIDS-related mortalities. ${ }^{4}$ After the introduction of antiretroviral therapy (ART), the nature of the HIV/AIDS pandemic has changed from a deadly disease to a chronic manageable health condition, and there are reports coming out showing signs of stabilization of the disease with a decrease in morbidity and mortality. Safe and effective ART helps to improve the quality of life, reduce HIV-related morbidity, increase survival, decrease HIVrelated deaths, prevent emergence of drug resistance, and decrease the number of orphanages caused by HIV/AIDS and the incidence of the disease. ${ }^{5}$

Quality of service is a fundamental concept in bringing about the ideal health outcome in response to ART through a sustainable, safe, and effective service. ${ }^{6}$ Evaluation of patient satisfaction, with respect to their expectation, with the pharmaceutical care provided is an important part of the health services and will help identify specific areas of pharmaceutical care that needs improvement. Many studies have supported the notion that patients' expectation from the pharmaceutical care varies significantly by many factors, including the type of pharmacy practice site $^{7}$ and age. ${ }^{8}$ Many patients also expect the pharmacist to communicate and share responsibility with the physician for providing a better pharmaceutical care. ${ }^{9}$ Satisfaction can be defined as the degree to which desired goals have been achieved. ${ }^{10,11}$ Patient satisfaction has been considered as an important part when evaluating the health outcomes and quality of care. ${ }^{12,13}$ Furthermore, a satisfied patient is more likely to develop a longer lasting rapport with their health care provider, leading to better compliance and continuity of care. ${ }^{14,15}$ An individual who fails to take the ART due to dissatisfaction will end up in developing resistant strains to the drugs in a matter of few minutes. ${ }^{16-19}$ Measurements of patient satisfaction could also help to assess the performance of health service provision and predict treatment adherence and outcomes. ${ }^{20}$ Besides, it will enhance appropriate communication and build stronger health worker-patient relationship based on identified gaps and barriers to effective performance of HIV/AIDS prevention and control programs from the patients' perspective. Although several studies have reported challenges with HIV/AIDS prevention and control programs, ${ }^{21-23}$ data regarding the magnitude and patterns of patients' expectation from and satisfaction with the pharmaceutical services are still scarce in Ethiopia. This study aimed at assessing HIV/AIDS patients' expectation from and satisfaction with the pharmaceutical service delivered at Gondar University Referral Hospital (GURH).

\section{Patients and methods Study design and setting}

An institution-based cross-sectional study was employed to assess the level of expectations from and satisfaction of HIV/AIDS patients with the pharmaceutical services provided by GURH-ART pharmacy. GURH is one of the oldest teaching hospitals in the country with $>400$ beds and a range of specialties, including pediatrics, surgery, gynecology, psychiatry, dermatology, dentistry, ophthalmology, and pharmacy (inpatient, outpatient, ART, and emergency). The study was conducted from May 11 to 25, 2015.

\section{Sample size determination and sampling procedure}

The sample size was determined by using a single mean formula. $^{24}$

$$
\begin{aligned}
n & =Z^{2} \times p(1-p) / d^{2} \\
& =(1.96)^{2} \times 0.745(1-0.745) /(0.05)^{2} \\
& =291.92 \approx 292
\end{aligned}
$$

where $n$ is the required number of sample size, $Z$ is the standard normal distribution designed $95 \%$ confidence, usually $Z=1.96, p$ is the percentage of patient satisfaction in pharmacy service from previous study in Ethiopia, which is 0.745 , and $d$ is the degree of accuracy/allowable error, usually $5 \%$.

By expecting $74.5 \%$ of overall satisfaction at $95 \%$ confidence interval considering previous studies, ${ }^{6,25,26} 292$ patients were interviewed. For obtaining statistically significant representative of the population who has been visiting the pharmacy, simple random sampling was used. The average daily patient flow to the pharmacy was estimated to be $\sim 80$, and the number of patients to be interviewed during the 15 days of data collection was 20. By dividing the daily patient flow to the pharmacy with the number of patients to be surveyed per day, every fourth patient was approached to be interviewed and participate into the study. The first patient was selected daily through simple random sampling from one up to four and continuing with every fourth number until the daily sample limit was reached.

All adult patients (18 years and older) living with HIV/AIDS who were willing to give consent, able to listen oral Amharic language, and completed the interview process were included, while patients with uncontrolled psychiatric disease that leads to inability to complete the questionnaire and patients seeking emergency medical attention were excluded from the study. 


\section{Data collection and management}

The data collection tool used in the study was adopted and modified from previous studies. ${ }^{27,28}$ The questionnaire has three major parts. Part one assessed the sociodemographic characteristics of respondents. Part two included queries about expectations and satisfaction with the pharmaceutical services provided. It was further divided into two parts focusing on the sittings and services of the pharmacy. The satisfaction section contained 23 5-point Likert scale items; on the scale, "1" stood for rating of the item as "poor", while "2", "3", "4", and "5" stood for "fair", "good", "very good", and "excellent", respectively. Similarly, the section that focused on expectations of patients contained 155 -point Likert scale items, where "1" stood for rating of the item as "strongly disagree", while "2", "3", “4”, and "5" stood for "disagree", "neutral", "agree", and "strongly agree", respectively. Based on this, the mean levels of expectation and satisfaction of patients were calculated by averaging their ratings for the 15 and 23 parameters of measuring expectations and satisfaction, respectively. The resulting mean was interpreted by considering the closest Likert scale to it. The data were collected by four principal investigators through intervieweradministered questionnaires and face-to-face interviews by explaining the questions for those unable to read and write. The questionnaire, originally written in English, was translated to local language (Amharic) and back to English in order to ensure that the translated version gives the proper meaning. The content validity of the tool (questionnaire) was confirmed by a team of experts including a senior physician, epidemiologist, and clinical pharmacist. The questionnaire was pretested on $15 \mathrm{HIV}$ patients prior to the gross data collection, which were excluded from final study, and relevant modifications were instituted. In the pretest, there was an item measuring patient's satisfaction on electronic medication dispensing service availability. Since our health care system is not well developed and patients with ARV should have a counseling service before they refill their medications to assess their adherence and monitor side effects, we omitted this question from the final data collection tool.

\section{Statistical analysis}

The final data collection tool was ensured for completeness, and the responses were entered into and analyzed by the Statistical Package for the Social Sciences software Version 21.0 for Windows. In the study, sociodemographic characteristics, satisfaction, and expectation level of patients were described using frequencies, percentage, mean, and SD. Student's $t$-test and one-way analysis of variance (ANOVA) were used to evaluate the difference in expectation and satisfaction level of patients. $P$-value $<0.05$ and $95 \%$ confidence interval were used as cutoff points for determining the statistical significance of associations among different variables.

\section{Ethical considerations}

This study was approved by the Ethical Committee of the University of Gondar. Written informed consent from the respondents was also obtained before conducting this study. Respondents' information obtained was kept confidential. Respondents were also told that participation was voluntary.

\section{Results \\ Sociodemographic characteristics of respondents}

Of the 292 patients who were interviewed, 287 completed the questionnaire, giving a response rate of $98.3 \%$. The reasons for nonparticipation were fear of stigmatization as some of the participants assume that participating in this study may endanger them to be stigmatized by the community since most of the participants are not willing to share their ARV status to other persons. The mean ages of respondents were $34 \pm 12$ years with majority of them between 18 years and 30 years of age $(52.3 \%)$. More than half $(58.9 \%)$ of respondents were females and live in urban area (66.6\%). Nearly half (49.5\%) of the respondents were married, and majority (77.4\%) were Orthodox Christians. Approximately 47\% of the respondents reported an average monthly income of $<500$ Ethiopian birr. Majorities of the respondents (66.6\%) visit the ART pharmacy for self-care, while $33.4 \%$ of respondents visit for self-care as well as for their family and relatives. Other sociodemographic characteristics of respondents are depicted in Table 1.

\section{Patients' satisfaction toward the pharmaceutical service}

The respondents had relatively low satisfaction on comfort and convenience of waiting area, private counseling room, and waiting time until they get the service with a mean satisfaction of 2.86, 2.88, and 2.99, respectively. But they were relatively satisfied on convenience of the pharmacy location with a mean satisfaction of 3.47 (Table 2). Among the parameters the respondents were rated, the lowest satisfaction level was observed in question related to taking important drug and health-related history from the patients with the mean satisfaction rate of 2.46. Most respondents also stated that pharmacy professionals did not tell about 
Table I Distribution of respondents by sociodemographic characteristics, GURH, 2015

\begin{tabular}{|c|c|}
\hline Variables & Frequency (\%) \\
\hline Age (mean $\pm S D$ ), years & $34 \pm 12$ \\
\hline \multicolumn{2}{|l|}{ Age group, years } \\
\hline $18-30$ & $150(52.3)$ \\
\hline $31-40$ & 61 (2I.3) \\
\hline $4 I-50$ & 40 (13.9) \\
\hline $51-60$ & $24(8.4)$ \\
\hline$>60$ & $12(4.2)$ \\
\hline \multicolumn{2}{|l|}{ Sex } \\
\hline Female & $169(58.9)$ \\
\hline Male & I I 8 (4I.I) \\
\hline \multicolumn{2}{|l|}{ Area of residence } \\
\hline Urban & $191(66.6)$ \\
\hline Rural & $96(33.4)$ \\
\hline \multicolumn{2}{|l|}{ Marital status } \\
\hline Married & $142(49.5)$ \\
\hline Single & $120(4 \mid .8)$ \\
\hline Separated & $15(5.2)$ \\
\hline Widowed & $10(3.5)$ \\
\hline \multicolumn{2}{|l|}{ Educational status } \\
\hline Illiterate & $54(18.8)$ \\
\hline Primary school (Grades I-8) & $67(23.3)$ \\
\hline High school (Grades 9-12) & 7I (24.7) \\
\hline Diploma & $36(12.5)$ \\
\hline Degree & $51(17.8)$ \\
\hline Postgraduate & $8(2.8)$ \\
\hline \multicolumn{2}{|l|}{ Religion } \\
\hline Orthodox & $222(77.4)$ \\
\hline Muslim & $48(16.7)$ \\
\hline Protestant & $13(4.5)$ \\
\hline Catholic & $19(0.3)$ \\
\hline Other & $3(I)$ \\
\hline \multicolumn{2}{|l|}{ Ethnicity } \\
\hline Amhara & $257(89.55)$ \\
\hline Oromo & $8(2.8)$ \\
\hline Tigray & $19(6.6)$ \\
\hline Other ${ }^{\mathrm{b}}$ & $3(I)$ \\
\hline \multicolumn{2}{|l|}{ Occupation } \\
\hline Student & 7I (24.7) \\
\hline Unemployed & $13(4.5)$ \\
\hline Government employed & $68(23.7)$ \\
\hline Farmer & $45(15.7)$ \\
\hline Housewife & $43(15.0)$ \\
\hline Merchant & $24(8.4)$ \\
\hline Otherc & $23(8.0)$ \\
\hline \multicolumn{2}{|l|}{ Monthly income in ETB } \\
\hline$<500$ & $135(47)$ \\
\hline $500-999$ & $37(12.9)$ \\
\hline $1,000-1,499$ & $35(12.2)$ \\
\hline $1,500-2,499$ & $53(18.5)$ \\
\hline$>2,500$ & $27(9.4)$ \\
\hline \multicolumn{2}{|l|}{ Frequency of visit } \\
\hline First time & $8 \mathrm{I}(28.2)$ \\
\hline Repeat & $206(71.8)$ \\
\hline \multicolumn{2}{|l|}{ ART pharmacy service sought for } \\
\hline Self & $191(66.6)$ \\
\hline Self and others (family/relatives) & $96(33.4)$ \\
\hline
\end{tabular}

Notes: ajehovah's witness. 'Agew, Kimant, and Debub (Wolayita, Sidama). 'Private workers and labor workers.

Abbreviations: GURH, Gondar University Referral Hospital; ETB, Ethiopian birr; ART, antiretroviral therapy. the side effects of ART medications, how to mitigate those side effects, and about drug-drug and drug-food interactions with a mean satisfaction level of $2.79,2.53$, and 2.63, respectively, but they were satisfied with the use of language for communication by the pharmacists, which is easy and understandable, with a mean satisfaction level of 3.90 (Table 3).

The overall satisfaction was described by parameters for pharmacy setting and services. The overall levels of satisfaction in pharmaceutical service (pharmacy setting and services) among respondents were 3.13. Based on the Student's $t$-test performed on sociodemographic variables, statistically significant satisfaction difference with respect to the pharmacy setting was found in areas of residence. One-way ANOVA test showed significant differences among respondents with different marital, occupational, and educational status as well as religion (Tables 4 and 5).

\section{Patients' expectation from the pharmaceutical service}

Among the parameters rated by the patients related to the pharmacy setting, majority of the participants expected convenient and comfortable waiting area (agree and strongly agree $=71.4 \%$ ) and sufficient number of ART units (agree and strongly agree $=65.5 \%$ ). A significant number of respondents (agree and strongly agree $=84.7 \%$ ) expected comfortable and convenient private counseling room (Table 6). Most respondents (agree and strongly agree $=69.7 \%$ ) expected pharmacy professionals to advise/counsel them in detail on how each of their medication(s) supposed to help, check their prescription for completeness, accuracy, and legality (agree and strongly agree $=75.9 \%$ ), and advise them on their diseases and provide general tips on healthy life style (agree and strongly agree $=66.2 \%$ ). Majority of the respondents expected the pharmacy for adequate supply of the ARV drug(s) (agree and strongly agree $=84.7 \%$ ) and the pharmacy professionals to keep reasonable privacy during discussion of their conditions (agree and strongly agree $=84.7 \%$ ) (Table 7). The overall mean expectation of the patients toward pharmacy setting and services was 3.62 on a 5-point Likert scale (Tables 6 and 7). There was a statistically significant difference $(t=3.415, P=0.001)$ in the overall expectation toward setting and services of ART pharmacy between respondents whose residence was in Gondar town and out of Gondar town. The mean expectation of the respondents who live outside of Gondar town (3.38) was lower than that of the respondents who live in Gondar town (3.73) (Table 8). 
Table 2 Percentage distribution of patients' satisfaction toward pharmacy setting, GURH, 2015

\begin{tabular}{|c|c|c|c|c|c|}
\hline Variables & Total (\%) & $\begin{array}{l}\text { Poor to fair, } \\
\text { n (\%) }\end{array}$ & Good, n (\%) & $\begin{array}{l}\text { Very good and } \\
\text { excellent, } n(\%)\end{array}$ & Mean \\
\hline The convenience of ART pharmacy location & $287(100)$ & $88(30.66)$ & $172(59.93)$ & $27(9.4)$ & 3.47 \\
\hline Comfort and convenience of waiting area & $287(100)$ & $16 \mid(56.1)$ & $100(34.84)$ & $26(9.06)$ & 2.86 \\
\hline The cleanliness and tidiness of ART pharmacy & $287(100)$ & $103(35.89)$ & I 36 (47.39) & $48(16.72)$ & 3.41 \\
\hline Provision of clear and organized service & $287(100)$ & $14 \mid(49.1)$ & $108(37.6)$ & $38(13.2)$ & 3.15 \\
\hline Comfort and convenience of private counseling room & $287(100)$ & $157(54.7)$ & $102(35.5)$ & $28(9.8)$ & 2.88 \\
\hline Waiting time until getting the service & $287(100)$ & $17(5.92)$ & III (38.68) & $159(55.40)$ & 3.81 \\
\hline
\end{tabular}

Abbreviations: GURH, Gondar University Referral Hospital; ART, antiretroviral therapy.

\section{Discussion}

Assessing the level of expectations and satisfaction of patients with their health care services provided has become important worldwide. ${ }^{29}$ Surveys assessing level of patients' expectations and satisfaction are essential in obtaining an inclusive understanding of the patients' need and their opinion of the service received. This will help to fill the gap between what the patients need and what they really get. ${ }^{30}$

Among the 287 participants, the overall mean satisfaction toward pharmacy setting and pharmaceutical services was found to be average (3.13), and the overall satisfaction of the respondents was $54.7 \%$. Similar finding was reported from the study done on quality assessment of ART service in private hospitals in Addis Ababa, by recruiting 183 ART clients from six private hospitals $(54.2 \%){ }^{6}$ Nearly half of the respondents in this study were satisfied by the convenience and comfort of ART pharmacy waiting area. This was very much lower than the study reported in South Africa and Addis Ababa specialist ART units, which were $86 \%$ and $84.6 \%$ for the same question, respectively. ${ }^{31,32}$ The reason attributed for this was the lack of organized ART care structures in the hospital. Together with this, majority of the respondents in

Table 3 Patients' satisfaction toward pharmacy services, GURH, 2015

\begin{tabular}{|c|c|c|c|c|c|}
\hline Variables & Total (\%) & $\begin{array}{l}\text { Poor to fair, } \\
\text { n (\%) }\end{array}$ & Good, n (\%) & $\begin{array}{l}\text { Very good and } \\
\text { excellent, } n(\%)\end{array}$ & Mean \\
\hline Taking time to listen to what you want & $287(100)$ & $137(47.7)$ & $74(25.8)$ & $76(26.5)$ & 3.21 \\
\hline $\begin{array}{l}\text { Taking important drug and health-related history } \\
\text { from the patient }\end{array}$ & $287(100)$ & $207(72.1)$ & $71(24.7)$ & $9(3.2)$ & 2.46 \\
\hline $\begin{array}{l}\text { Briefly explaining how to take the ARV } \\
\text { medications }\end{array}$ & $287(100)$ & $175(6 \mid)$ & $95(33.1)$ & $17(5.9)$ & 2.80 \\
\hline $\begin{array}{l}\text { Providing adequate information about ARV } \\
\text { medication precautions and side effects }\end{array}$ & $287(100)$ & $178(62)$ & $90(31.3)$ & $19(6.7)$ & 2.79 \\
\hline $\begin{array}{l}\text { Providing adequate information about ARV } \\
\text { medication drug-drug and drug-food interactions }\end{array}$ & $287(100)$ & $188(65.5)$ & $80(27.8)$ & $19(6.7)$ & 2.63 \\
\hline Treating the patient with dignity and respect & $287(100)$ & $97(33.8)$ & $156(54.4)$ & $34(11.8)$ & 3.43 \\
\hline $\begin{array}{l}\text { Availability of the pharmacy professionals during } \\
\text { the time of visit }\end{array}$ & $287(100)$ & $75(26.1)$ & $164(57.1)$ & $48(16.8)$ & 3.65 \\
\hline $\begin{array}{l}\text { Provision of ARV drug information in written form } \\
\text { whenever needed }\end{array}$ & $287(100)$ & $208(72.5)$ & $67(23.3)$ & $12(4.2)$ & 2.54 \\
\hline Keeping privacy during counseling & $287(100)$ & $129(45)$ & $120(4 \mid .8)$ & $38(13.2)$ & 3.38 \\
\hline Providing service equally to all patients & $287(100)$ & $69(24)$ & $165(57.5)$ & $53(18.5)$ & 3.70 \\
\hline $\begin{array}{l}\text { Providing information on how to solve ARV } \\
\text { medication-related side effects }\end{array}$ & $287(100)$ & $199(69.3)$ & $69(24)$ & $19(6.7)$ & 2.53 \\
\hline Answering queries you may have & $287(100)$ & $127(44.3)$ & $124(43.2)$ & $36(12.5)$ & 3.37 \\
\hline $\begin{array}{l}\text { Use of language by the pharmacist is easy and } \\
\text { understandable }\end{array}$ & $287(100)$ & $53(18.5)$ & $166(57.8)$ & $68(23.7)$ & 3.90 \\
\hline $\begin{array}{l}\text { Label my medicines in readable and understandable } \\
\text { instruction }\end{array}$ & $287(100)$ & $144(50.2)$ & $112(39)$ & $31(10.8)$ & 3.10 \\
\hline Giving medicines with appropriate packaging & $287(100)$ & $156(54.3)$ & $103(35.9)$ & $28(9.8)$ & 3.00 \\
\hline $\begin{array}{l}\text { Telling information about proper storage of } \\
\text { medications }\end{array}$ & $287(100)$ & I 66 (57.8) & 91 (31.7) & $30(10.5)$ & 2.84 \\
\hline Availability of the required medicines & $287(100)$ & $17(5.9)$ & $82(28.6)$ & $188(65.5)$ & 3.94 \\
\hline
\end{tabular}

Abbreviations: GURH, Gondar University Referral Hospital; ARV, antiretroviral. 
Table 4 Test of statistical significance (Student's t-test) of variation in the mean satisfaction level of patients by sociodemographic characteristics, GURH, 2015

\begin{tabular}{|c|c|c|c|c|c|c|}
\hline \multirow[t]{2}{*}{ Variables } & \multicolumn{2}{|c|}{$\begin{array}{l}\text { Satisfaction with } \\
\text { setting }\end{array}$} & \multicolumn{2}{|c|}{$\begin{array}{l}\text { Satisfaction with } \\
\text { services }\end{array}$} & \multicolumn{2}{|c|}{ Overall satisfaction } \\
\hline & Mean (SD) & $P$-value & Mean (SD) & $P$-value & Mean (SD) & $P$-value \\
\hline Sex & & 0.584 & & 0.179 & & 0.274 \\
\hline Female & $3.16(0.863)$ & & $3.04(0.586)$ & & $3.10(0.568)$ & \\
\hline Male & $3.22(0.790)$ & & $3.14(0.699)$ & & $3.18(0.639)$ & \\
\hline Residence & & $0.011 *$ & & 0.673 & & 0.125 \\
\hline Gondar town & $3.09(0.860)$ & & $3.09(0.634)$ & & $3.09(0.622)$ & \\
\hline Out of Gondar town & $3.36(0.749)$ & & $3.06(0.642)$ & & $3.21(0.542)$ & \\
\hline Frequency of visit & & 0.544 & & $0.025^{*}$ & & 0.443 \\
\hline First time & $3.23(0.878)$ & & $2.95(0.610)$ & & $3.09(0.609)$ & \\
\hline Repeat & $3.16(0.815)$ & & $3.13(6.39)$ & & $3.15(0.595)$ & \\
\hline Service sought for & & 0.490 & & 0.520 & & 0.890 \\
\hline Self & $3.16(0.861)$ & & $3.09(0.678)$ & & $3.13(0.629)$ & \\
\hline Both (self and others [family/relatives]) & $3.23(0.775)$ & & $3.05(0.544)$ & & $3.14(0.536)$ & \\
\hline
\end{tabular}

Note: $*$-value $<0.05$.

Abbreviation: GURH, Gondar University Referral Hospital.

this study were dissatisfied by the comfort and convenience of private counseling area. This might have resulted from the absence of separate private counseling area/room in the pharmacy. However, in the study conducted by Selente et al, ${ }^{31}$ most of the study participants were satisfied by the counseling room and the ART service provided by the hospitals, since most of the ART clinics and pharmacies are supported by nongovernmental organizations such as the US President's Emergency Plan For AIDS Relief. In contrast, our findings were higher than a study done in Kenya where two-thirds of the clients were not satisfied by the ART service provided; these might be due to insufficient infrastructure available to counseling service. Almost all (95.1\%) the HIV/AIDS patients were satisfied with waiting time to get service. This could be explained by the fact that pharmacy professionals do not provide detailed information about ARV drugs, as supported by other findings in this study (advice about ART medications precautions and side effects [mean $=2.79$ ], drug-food interactions [mean $=2.63$ ], and proper storage condition [mean $=2.84]$ ). This finding was in agreement with the study carried out in Addis Ababa specialist ART units (93.33\%). ${ }^{32}$ Compared to a study conducted in Kenya, this finding was much lower. ${ }^{33}$ A large proportion of the participants reported that they were, in general, satisfied regarding treating the patient with dignity and respect (66.2\%) and good communication (81.5\%) with the attending pharmacy professionals. This finding was in agreement with a study conducted in South Africa on patient satisfaction at accredited ART sites (98\%); they reported that health professionals were kind, polite, respectful, and attentive during consultations. ${ }^{31}$ Similarly, a patient satisfaction survey conducted in Singapore, Tigray, and Jimma on clients' satisfaction with ART services showed that the courtesy and respect displayed by health professionals have a positive impact on patient satisfaction; in this regard, most of the questions on level of satisfaction regarding the skill, attitude, and interaction of ART staffs were answered positively. ${ }^{25,26,34}$ The result can be attributed to different reasons; the major reason could be due to the better attention given by Federal ministry of health and regional health bureau and existence of nongovernmental organizations specifically working on ART care such as Management Sciences for Health, Pharmaceuticals Fund and Supply Agency, and System for Improved Access to Pharmaceuticals and Services. Almost all $(94.1 \%)$ the study participants were satisfied with the availability of required ART medications. This could be explained by having free supply of ARV drugs that will definitely take their level of satisfaction to higher level. Similar high levels of satisfactions from different aspects of ART pharmacy services were reported by studies in Nigeria and Addis Ababa. ${ }^{6,32,35}$ More than half of the respondents were dissatisfied by information about the storage of medicines and labeling instructions that were not provided to them. This might have resulted because of pharmacy professionals' unawareness in delivering such information with a thought that patients do know this information, or it might be related to the common dispensing malpractice. ${ }^{36,37} \mathrm{In}$ one-way ANOVA test, statistically significant satisfaction differences were found among different educational levels, marital status, and religions of the participants. On post hoc 
Table 5 Test of statistical significance (one-way ANOVA) of the variation in the mean satisfaction level of patients by sociodemographic characteristics, GURH, 2015

\begin{tabular}{|c|c|c|c|c|c|c|}
\hline \multirow[t]{2}{*}{ Variables } & \multicolumn{2}{|c|}{ Satisfaction with setting } & \multicolumn{2}{|c|}{ Satisfaction with services } & \multicolumn{2}{|c|}{ Overall satisfaction } \\
\hline & Mean (SD) & $P$-value & Mean (SD) & $P$-value & Mean (SD) & $P$-value \\
\hline Age (years) & & 0.723 & & 0.386 & & 0.476 \\
\hline $18-30$ & $3.12(0.889)$ & & $3.03(0.613)$ & & $3.08(0.636)$ & \\
\hline $31-40$ & $3.20(0.835)$ & & $3.15(0.635)$ & & $3.18(0.577)$ & \\
\hline $4 I-50$ & $3.29(0.706)$ & & $3.05(0.653)$ & & $3.17(0.530)$ & \\
\hline $5 I-60$ & $3.27(0.663)$ & & $3.11(0.637)$ & & $3.19(0.522)$ & \\
\hline$>60$ & $3.33(0.848)$ & & $3.36(0.842)$ & & $3.35(0.585)$ & \\
\hline Marital status & & 0.055 & & 0.223 & & $0.047^{*}$ \\
\hline Married & $3.29(0.777)$ & & $3.15(0.702)$ & & $3.22(0.580)$ & \\
\hline Unmarried & $3.04(0.901)$ & & $2.99(0.533)$ & & $3.02(0.617)$ & \\
\hline Divorced & $3.08(0.730)$ & & $3.19(0.6 \mathrm{I})$ & & $3.13(0.530)$ & \\
\hline Widowed & $3.50(0.207)$ & & $3.01(0.784)$ & & $3.26(0.565)$ & \\
\hline Education status & & $0.00 I^{*}$ & & 0.180 & & $0.002^{*}$ \\
\hline Illiterate & $3.35(0.7 \mid 8)$ & & $3.04(0.670)$ & & $3.19(0.556)$ & \\
\hline Primary school (Grades I-8) & $3.37(0.738)$ & & $3.22(0.622)$ & & $3.29(0.515)$ & \\
\hline High school (Grades 9-12) & $3.23(0.775)$ & & $3.15(0.616)$ & & $3.19(0.587)$ & \\
\hline College/diploma & $3.04(0.807)$ & & $2.97(0.686)$ & & $3.00(0.627)$ & \\
\hline Degree holders & $2.76(0.994)$ & & $2.96(0.606)$ & & $2.86(0.659)$ & \\
\hline Postgraduates & $3.4 \mathrm{I}(0.972)$ & & $2.95(0.527)$ & & $3.17(0.568)$ & \\
\hline Religion & & $0.002^{*}$ & & $0.025^{*}$ & & $0.004^{*}$ \\
\hline Orthodox & $3.25(0.829)$ & & $3.05(0.644)$ & & $3.15(0.615)$ & \\
\hline Muslim & $3.11(0.699)$ & & $3.27(0.616)$ & & $3.19(0.440)$ & \\
\hline Protestant & $2.62(0.998)$ & & $3.06(0.392)$ & & $2.84(0.601)$ & \\
\hline Other & $1.833(0.144)$ & & $2.23(0.144)$ & & $2.03(0.000)$ & \\
\hline Ethnicity & & 0.101 & & 0.132 & & 0.498 \\
\hline Amhara & $3.20(0.83 \mathrm{I})$ & & $3.07(0.635)$ & & $3.14(0.601)$ & \\
\hline Oromo & $2.91(0.915)$ & & $3.56(0.542)$ & & $3.23(0.618)$ & \\
\hline Tigray & $2.89(0.76 \mathrm{I})$ & & $3.02(0.635)$ & & $2.96(0.577)$ & \\
\hline Other & $4(0.750)$ & & $2.75(0.661)$ & & $3.37(0.45 \mathrm{I})$ & \\
\hline Occupation & & $0.002^{*}$ & & 0.221 & & $0.002^{*}$ \\
\hline Student & $2.87(0.997)$ & & $2.96(0.547)$ & & $2.92(0.645)$ & \\
\hline Laborer & $3.08(0.892)$ & & $3.05(0.633)$ & & $3.06(0.624)$ & \\
\hline Government employee & $3.11(0.85 I)$ & & $3.02(0.627)$ & & $3.06(0.605)$ & \\
\hline Farmer & $3.39(0.694)$ & & $3.07(0.609)$ & & $3.23(0.491)$ & \\
\hline Housewife & $3.35(0.625)$ & & $3.24(0.698)$ & & $3.29(0.554)$ & \\
\hline Merchant & $3.42(0.789)$ & & $3.14(0.708)$ & & $3.28(0.636)$ & \\
\hline Other & $3.49(0.566)$ & & $3.29(0.743)$ & & $3.39(0.430)$ & \\
\hline Monthly income (birr) & & 0.133 & & 0.763 & & 0.316 \\
\hline$<500$ & $3.08(0.876)$ & & $3.05(0.602)$ & & $3.06(0.617)$ & \\
\hline 500-999 & $3.46(0.663)$ & & $3.11(0.708)$ & & $3.28(0.55 \mathrm{I})$ & \\
\hline $1,000-1,499$ & $3.14(0.777)$ & & $3.20(0.630)$ & & $3.17(0.558)$ & \\
\hline $1,500-2,499$ & $3.27(0.735)$ & & $3.09(0.694)$ & & $3.18(0.597)$ & \\
\hline$>2,500$ & $3.23(1.005)$ & & $3.02(0.617)$ & & $3.13(0.559)$ & \\
\hline
\end{tabular}

Note: $* P$-value $<0.05$.

Abbreviations: ANOVA, analysis of variance; GURH, Gondar University Referral Hospital.

analysis, higher level of satisfaction was reported among illiterate respondents than in those having higher education, and similarly, higher level of satisfaction was reported among married respondents compared to unmarried ones. Similar findings were reported by studies conducted in Kenya and Tigray. ${ }^{25,33}$ The higher level of satisfaction among the illiterate and married respondents could be associated with lesser understanding of the significance of details of the functions in the pharmacy and the services they deserved to get.

More than two-thirds (76\%) of the respondents agreed or strongly agreed that they expected pharmacy professionals to check the completeness, accuracy, and legality of the prescriptions. This could be related to the fact that prescription refill is the most common duty of pharmacy professionals 
Table 6 Percentage distribution of respondents' expectation toward pharmacy setting, GURH, 20 I5

\begin{tabular}{|c|c|c|c|c|c|}
\hline Variables & Total (\%) & $\begin{array}{l}\text { Strongly disagree } \\
\text { and disagree, n (\%) }\end{array}$ & $\begin{array}{l}\text { Neutral, } \\
\text { n (\%) }\end{array}$ & $\begin{array}{l}\text { Agree and strongly } \\
\text { agree, n (\%) }\end{array}$ & Mean \\
\hline Comfort and convenience of waiting area & $287(100)$ & $64(22.3)$ & $18(6.3)$ & $205(71.4)$ & 3.62 \\
\hline Comfort and convenience of private counseling room & $287(100)$ & $25(8.7)$ & $19(6.6)$ & $243(84.7)$ & 4.15 \\
\hline Sufficient number of ART units & $287(100)$ & $78(27.2)$ & $21(7.3)$ & $188(65.5)$ & 3.58 \\
\hline Overall appearance appropriate for work & $287(100)$ & $45(15.7)$ & $23(8)$ & $219(76.3)$ & 3.97 \\
\hline
\end{tabular}

Abbreviations: GURH, Gondar University Referral Hospital; ART, antiretroviral therapy.

known to patients as it is the major role currently in Ethiopia. Approximately $65.5 \%$ and $82.9 \%$ of the respondents agreed or strongly agreed that they expected sufficient number of ART units and adequate supply of ART drugs, respectively. This finding was relatively lower compared to a study conducted in Addis Ababa, which was 94.82\% and 91.12\%, respectively. More than two-thirds (69.7\%) of the respondents were expected provision of adequate drug-related information. This finding was also lower compared to a study conducted in Addis Ababa, which reported 95.56\%. ${ }^{32}$ A statistically significant difference was found in the overall expectation toward setting and pharmacy services between the respondents whose residence was in Gondar town and out of Gondar town. The mean expectation of the respondents whose residence was out of Gondar town (3.38) was lower than those who live in Gondar town (3.73), with a $P$-value of 0.001 . This might be because of better awareness and access to health-related information among patients who live in Gondar town, which in turn pushed up their expectations. The study has some limitations that should be considered while interpreting the results. The fact that each/specific pharmaceutical service patients got was not assessed in detail may interfere with this study's ability to assess the overall level of expectations and satisfaction of patients with regard to the pharmaceutical services.

\section{Limitations of the study}

The study has some limitations that should be taken into account while interpreting the results. As this study was done in a single center and was cross sectional in nature, the findings cannot be generalized to other similar settings in Ethiopia and do not have the nature of in-depth description that could have been realized if qualitative methods or comparative studies (which includes a provider aspect) were employed. In addition, some of the respondents may provide extreme responses compared to others, due to the motivations and beliefs of the respondents, and might have affected the finding.

\section{Conclusion}

In this study, the overall satisfaction level of respondents with pharmaceutical service (pharmacy setting and services)

Table 7 Percentage distribution of respondents' expectation toward pharmacy services, GURH, 2015

\begin{tabular}{|c|c|c|c|c|c|}
\hline Variables & Total (\%) & $\begin{array}{l}\text { Strongly disagree } \\
\text { and disagree, n (\%) }\end{array}$ & $\begin{array}{l}\text { Neutral, } \\
\text { n (\%) }\end{array}$ & $\begin{array}{l}\text { Agree and strongly } \\
\text { agree, } n(\%)\end{array}$ & Mean \\
\hline $\begin{array}{l}\text { Checking my prescription for completeness, } \\
\text { accuracy, and legality }\end{array}$ & $287(100)$ & $34(11.8)$ & $35(12.2)$ & $218(76)$ & 3.83 \\
\hline $\begin{array}{l}\text { Advise me how well my medical conditions are } \\
\text { controlled }\end{array}$ & $287(100)$ & $70(24.4)$ & $57(19.9)$ & $160(55.7)$ & 3.39 \\
\hline $\begin{array}{l}\text { Advise/counsel me in detail how each of my } \\
\text { medication supposed to help me }\end{array}$ & $287(100)$ & $60(20.9)$ & $27(9.4)$ & $200(69.7)$ & 3.60 \\
\hline Offer me a choice of information sources & $287(100)$ & $73(25.4)$ & $49(17.1)$ & $165(57.5)$ & 3.41 \\
\hline Ask me if I have concerns about medication & $287(100)$ & $121(42.2)$ & $43(15)$ & $123(42.8)$ & 2.93 \\
\hline Pharmacy staff to be pleasant and courteous & $287(100)$ & $22(7.7)$ & $18(6.3)$ & $247(86)$ & 4.17 \\
\hline Reasonable privacy during discussing my condition & $287(100)$ & $25(8.7)$ & $19(6.6)$ & $243(84.7)$ & 4.15 \\
\hline $\begin{array}{l}\text { Advise me about my disease and provide general } \\
\text { advise on healthy life style }\end{array}$ & $287(100)$ & $58(20.2)$ & $39(13.6)$ & $190(66.2)$ & 3.57 \\
\hline $\begin{array}{l}\text { Involve me in decision making during the } \\
\text { provision of health care }\end{array}$ & $287(100)$ & $60(20.9)$ & $55(19.2)$ & 172 (59.9) & 3.48 \\
\hline Adequate supply of drugs & $287(100)$ & $32(11.2)$ & $17(5.9)$ & $238(82.9)$ & 4.12 \\
\hline $\begin{array}{l}\text { Label my medications with appropriate } \\
\text { instructions }\end{array}$ & $287(100)$ & $96(33.4)$ & $12(4.2)$ & $179(62.4)$ & 3.52 \\
\hline
\end{tabular}

Abbreviation: GURH, Gondar University Referral Hospital. 
Table 8 Student's $t$-test of differences between categories of respondents in expectation toward pharmacy, GURH, 2015

\begin{tabular}{llc}
\hline Variables & $\begin{array}{l}\text { Overall expectation } \\
\text { with setting and } \\
\text { services }\end{array}$ & \\
\cline { 2 - 3 } & Mean (SD) & P-value \\
\hline $\begin{array}{l}\text { Sex } \\
\quad \text { Female }\end{array}$ & $3.63(0.849)$ & 0.668 \\
$\quad$ Male & $3.59(0.819)$ & \\
Residence & $3.73(0.754)$ & $0.01 *$ \\
$\quad$ Gondar town & $3.38(0.940)$ & \\
$\quad$ Out of Gondar town & & \\
Frequency of visit & $3.60(0.84 I)$ & 0.817 \\
$\quad$ First time & $3.36(0.836)$ & \\
$\quad$ Repeat & $3.61(0.831)$ & 0.755 \\
Service sought for & $3.64(0.851)$ & \\
$\quad \begin{array}{l}\text { Self } \\
\text { Both (self and others [family/relatives]) }\end{array}$ &
\end{tabular}

Note: $* P$-value $<0.05$.

Abbreviation: GURH, Gondar University Referral Hospital.

provided at GURH was found to be low, while the overall respondents' expectation from the pharmaceutical services were exceedingly high. Lower satisfaction levels were reported regarding comfort and convenience of waiting area and private counseling room. The reported low satisfaction level parameters should be further studied to find appropriate solutions in solving the problems. The hospital should implement good dispensing practice systems in relation to the services and continuing professional development to professionals in order to improve the satisfaction of patients.

\section{Disclosure}

The authors report no conflicts of interest in this work.

\section{References}

1. Frezzini C, Leao JC, Porter S. Current trends of HIV disease of the mouth. J Oral Pathol Med. 2005;4:513-531.

2. WHO. World Health Statistics, Health-Related Millennium Development Goals Report. Geneva: WHO; 2013.

3. UNAIDS. Reducing HIV Stigma and Discrimination: A Critical Part of National AIDS Programs. Geneva: Joint United Nations Program on HIV/AIDS; 2007.

4. WHO [webpage on the Internet]. ETHIOPIA Update Sheet on HIV-AIDS Programme 2014. 2014. Available from: http://www.afro.who.int/ en/ethiopia/country-programmes/topics/4480-hivaids.html. Accessed August 20, 2015.

5. Oluwafemi O. Oguntibeju: quality of life of people living with HIV and AIDS and antiretroviral therapy. HIV AIDS (Auckl). 2012;4:117-124.

6. Michael B. Evaluation of ART Service in Private Hospitals in Addis Ababa, Ethiopia [master's thesis]. Addis Ababa: Department of Community Health, Addis Ababa University; 2008.

7. Wiederholt JB, Rosowski PG. Antecedents of expectations for pharmacist information services measured in naturalistic settings. Mark Theor App. 1996;7:296.

8. Mackowiak JI, Manasse HR. Expectation vs. demand for pharmacy service. J Pharm Mark Manage. 1988;2:57-72.
9. Schommer JC. Ohio pharmacists' conceptual views and experiences regarding patient counselling. Drug Inf J. 1994;28:765-775.

10. Irish Society for Quality and Safety in Healthcare [webpage on the Internet]. Measurement of Patient Satisfaction Guidelines: Health Strategy Implementation Project. 2010. Available from: http://www.lenus.ie/ hse/handle/10147/43559?locale=ga. Accessed August 20, 2015.

11. Andaleeb SS, Siddiqui N, Khandakar S. Patient satisfaction with health services in Bangladesh. Health Policy Plan. 2007;22:263-273.

12. Donabedian A. Evaluating the quality of medical care. Milbank Mem Fund Q. 1966;44(suppl 3):166-206.

13. Ware Je JR, Davies AA, Stewart AL. The measurement and meaning of patient satisfaction. Health Med Care Serv Rev. 1978;1:3-15.

14. Larsen DE, Rootman I. Physician role performance and patient satisfaction. Soc Sci Med. 1976;10:29-32.

15. Fitzpatrick R. Surveys of patient satisfaction: designing a questionnaire and conducting a survey. Br Med J. 1991;302:1129-1132.

16. Federal HIV/AIDS Prevention and Control Office [homepage on the Internet]. Multi-Sectoral HIV/AIDS Response Monitoring and Evaluation Report: AIDS Resource Centre. 2010. Available from: http://www.etharc.org. Accessed August 20, 2015.

17. Mendoza AJ, Piechulek H, Al-Sabir A. Patient satisfaction and quality of health care in rural Bangladesh. Bull World Health Organ. 2001; 79:512-517.

18. Wu AW, Gifford A, Asch S, et al. Quality-of-Care Indicators for HIV/ AIDS: Disease Management Health Outcomes. 2000:7;315.

19. WHO. Client Satisfaction Evaluations: Work Book. 6th ed. Geneva: WHO; 2000

20. WHO. WHO Report on the Tuberculosis Epidemic: Use DOTS More Widely. Vol 97. Geneva: WHO; 1997:224.

21. Lifson AR, Demissie W, Tadesse A, et al. HIV/AIDS stigma-associated attitudes in a rural Ethiopian community: characteristics, correlation with HIV knowledge and other factors, and implications for community intervention. BMC Int Health Hum Rights. 2012;12:6.

22. Kurth AE, Celum C, Baeten JM, Vermund SH, Wasserheit JN. Combination HIV prevention: significance, challenges, and opportunities. Curr HIV/AIDS Rep. 2011;8(1):62-72.

23. Koenig S, Ivers LC, Pace S, et al. Successes and challenges of HIV treatment programs in Haiti: aftermath of the earthquake. HIV Ther. 2010; $4(2): 145-160$.

24. Lwanga SK, Lemeshow S. Sample Size Determination for Health Studies: A Practical Manual. Geneva: World Health Organization; 1991:1-5

25. Shewaye BT, Mesafint MA. Assessment of antiretroviral treatment (ART) care service provision in Tigray Region health centers, North Ethiopia. BMC Health Serv Res. 2015;15:368.

26. Getenet H, Haileamlak A. Client satisfaction with anti-retroviral therapy services. J Health Sci. 2008;2(18):21.

27. Larson LN, Rovers JP, MacKeigan LD. Patient satisfaction with pharmaceutical care: update of a validated instrument. J Am Pharm Assoc. 2002; 42:44-50.

28. Hovart N, Kos M. Development and initial validation of a partial satisfaction with pharmacy performance questionnaire (PSPPQ). Eval Health Prof. 2010;33:197-215.

29. Smith M, Engelbrecht B. Guide to Assessing Client Satisfaction at District Hospitals. A Collaborative Project between the National Department of Health and the Health Systems Trust; 2001. Available from: http://www.hst.org.za/sites/default/files/clientguide.pdf. Accessed April 17, 2014.

30. Iftighar AA, Shadiullah K, Mabibullah K, Muhammed A. Predictors of patient satisfaction. Gomal J Med Sci. 2011;9(2):183-188.

31. Selente B, Ogunsanwol DA, Helberg EA. Patients satisfaction at accredited antiretroviral treatment sites in the Gert Sibande District. Afr J Prim Health Care Fam Med. 2014;6(1):627.

32. Karunamoorthi K, Rajalakshmi M, Makesh SB, Yohannes A. HIV/AIDS patients satisfactory and their expectations with pharmacy service at specialist antiretroviral therapy (ART) units. Eur Rev Med Pharmacol Sci. 2009;13:331-339. 
33. Olive NM. Clients' Satisfaction with HIV/AIDS Care Services Offered at the Comprehensive Care Centre Machakos District Hospital, Kenya. [master's thesis]. Kenya: School of Health Sciences, Kenyatta University; 2012. Available from: http://ir-library.ku.ac.ke/bitstream/ handle/123456789/6872/Olive $\% 20 \% 20 \% 20$ Ndinda $\% 20 \% 20 \% 20$ Manyeti.pdf?sequence. Accessed August 20, 2015.

34. Molina JA, Lim GH, Seow E, Heng BH. Effects of survey mode on results of a patient satisfaction survey at the observation unit of an acute care hospital in Singapore. Ann Acad Med Singapore. 2009;38(6): 487-493.

35. Oche M, Raji M, Kaoje AU, Gana G, Ango JT, Okafoagu N. Clients' satisfaction with anti retroviral therapy services in a tertiary hospital in Sokoto, Nigeria. J AIDS HIV Res. 2013;5(9):328-333.
36. Food, Medicine and Healthcare Administration and Control Authority (FMHACA) of Ethiopia. Manual for Medicines Good Dispensing Practice. 2nd ed. Addis Ababa, Ethiopia; 2012. Available from: http://www. fmhaca.gov.et/documents/Medicines_Good_Dispensing_Manual_second_edition_2012.pdf. Accessed April 18, 2014.

37. Erku DA, Mekuria AB, Surur AS, Gebresillassie BM. Extent of dispensing prescription-only medications without a prescription in community drug retail outlets in Addis Ababa, Ethiopia: a simulated-patient study. Drug, Health care and Patient Safety. 2016;8:65-70.

\section{Publish your work in this journal}

Patient Preference and Adherence is an international, peer-reviewed, open access journal that focuses on the growing importance of patient preference and adherence throughout the therapeutic continuum. Patient satisfaction, acceptability, quality of life, compliance, persistence and their role in developing new therapeutic modalities and compounds to optimize clinical outcomes for existing disease states are major areas of interest for the journal. This journal has been accepted for indexing on PubMed Central. The manuscript management system is completely online and includes a very quick and fair peer-review system, which is all easy to use. Visit http://www. dovepress.com/testimonials.php to read real quotes from published authors.

Submit your manuscript here: http://www.dovepress.com/patient-preference-and-adherence-journal 